Immunol Rev. 2012 March ; 246(1): 239-253. doi:10.1111/j.1600-065X.2012.01107.x.

\title{
IKK Biology
}

Fei Liu, Yifeng Xia, Aaron S. Parker, and Inder M. Verma Laboratory of Genetics, The Salk Institute, La Jolla, CA, USA

\section{Summary}

The inhibitor of nuclear factor- $\mathrm{kB}$ (IкB) kinase (IKK) complex is the master regulator of the NF$\kappa \mathrm{B}$ signaling pathway. The activation of the IKK complex is a tightly regulated, highly stimulusspecific, and target-specific event that is essential for the plethora of functions attributed to NF$\kappa \mathrm{B}$. More recently, NF- $\kappa \mathrm{B}$ independent roles of IKK members have brought increased complexity to its biological function. This review highlights some of the major advances in the studies of the process of IKK activation and the biological roles of IKK family members, with a focus on NF- $\mathrm{BB}$ independent functions. Understanding these complex processes is essential for targeting IKK for therapeutics.

\section{Keywords}

IKK; NF-кB; NEMO

\section{Introduction}

Nuclear factor- $\kappa \mathrm{B}(\mathrm{NF}-\kappa \mathrm{B})$ is one of the major signaling pathways activated when cells are exposed to a variety of stimuli, including cytokines such as tumor necrosis factor (TNF) and interleukin 1 (IL-1), ultraviolet (UV) radiation, stress, and pathogenic assaults. In the

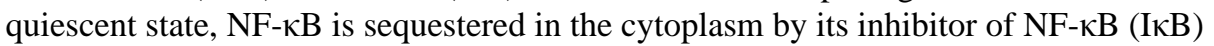
molecules (Reviewed in Hinz et al., this volume). Upon activation, IKB is phosphorylated by the IKB kinase (IKK) complex, composed of three major components: IKK1 (IKK $\alpha$ ), IKK2

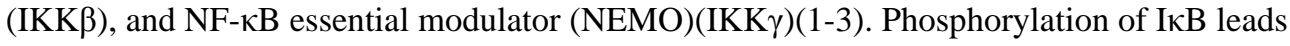
to its degradation, and subsequently, nuclear transport of NF- $\mathrm{KB}$ proteins initiates the downstream transcription of target genes. The 700-900 kDa multiprotein IKK holoenzyme therefore act as the master coordinator of NF- $\mathrm{KB}$ activation.

In addition to the canonical pathway of NF- $\mathrm{kB}$ activation mentioned above, in immune cells and under certain stimuli such as lymphtoxin- $\alpha / \beta, \mathrm{CD} 40 \mathrm{~L}$, and B-cell activating factor belonging to the tumor necrosis factor (TNF) family (BAFF), there exists an alternative pathway that requires NF- $\mathrm{KB}$-interacting kinase (NIK) and IKK1 homodimer mediated slow processing of p100 into p52 followed by nuclear translocation of RelB-p52 dimer (4, reviewed in Sun, this volume). Neither IKK2 nor NEMO deficiency affects this pathway (4-6). This pathway is much less well characterized than the canonical pathway, but it plays a critical role in the development of lymphoid organs responsible for the generation of B and T lymphocytes (7, reviewed in Kaileh \& Sen, this volume).

In recent years, many NF- $\mathrm{KB}$-independent functions of IKK complex members have been identified, some of which require the kinase activities, while others do not. These functions

Address for correspondence: Inder M. Verma, Laboratory of Genetics, The Salk Institute, 10010 North Torrey Pines Road, La Jolla, CA 92037, Tel.: +1 8584534100 x1462, Fax: +1 858558 7454, verma@ salk.edu. 
encompass tumorigenesis, immune functions, and cell cycle, just to name a few. They provide a bridge for crosstalk between NF- $\mathrm{KB}$ pathways with other important pathways such as $\mathrm{p} 53$ and mitogen-activated protein kinase (MAPK).

\section{Personal and historical narrative}

By early 1997, it was well established that IאBs were sequestered in the cytoplasm $(8,9)$, that I $\mathrm{KB} \alpha$ was phosphorylated on S32 and S36 from site-directed mutagenesis studies (10-14, Reviewed in Kanarek \& Ben-Neriah, this volume), and that polyubiquitination initiated the degradation of the IкBs by the 26s proteasome (14-16). The big question was, 'what induces I $\mathrm{B} \mathrm{B} \alpha$ phosphorylation?' Almost simultaneously, three groups published the characterization and subsequent cloning of IKK1 and IKK2, thus providing one of the missing links in the activation of NF- $\kappa B$ signaling pathway $(2,17-19)$. The IKKs were identified by fractionating whole cells extracts from TNF-stimulated HeLa cells using immunoprecipitation and anion exchange chromatography. Mercurio et al. additionally noted two separate bands of approximately 85 and $87 \mathrm{kDa}$ by SDS-PAGE silver staining from these purified fractions, corresponding to IKK1 and IKK2 (17). These extracts were then tested for I $\kappa \mathrm{B} \alpha$ and I $\kappa \mathrm{B} \beta$ phosphorylation activity by in vitro kinase assay using wildtype and phospho-mutant recombinant peptides. Mercurio et al. generated the corresponding IKK2 S177A/S181A and S177E/S181E constitutively inactive and active mutants, demonstrating the primary mechanism of activation of the IKK complex. The corresponding S176E/S180E IKK1 mutants were also minimally active. While both IKK1 and IKK2 are phosphorylated, the phosphorylation of serines in the activation loop of IKK2 is required for NF- $\mathrm{KB}$ activation, suggesting a more important role of IKK2 in what we now call the canonical NF- $\mathrm{KB}$ pathway. The third major polypeptide in the IKK complex, NEMO, was discovered simultaneous by two groups using very different approaches. Yamaoka et al. first reported the cloning of NEMO by complementation of human Tlymphotrophic virus-1 (HTLV-1) Tax-transformed rat fibroblasts that were unresponsive to all tested NF- $\mathrm{KB}$ activating stimuli. They demonstrated in vitro interactions of NEMO with IKK-2 and its essential role in Tax, TNF, phorbol myristate acetate (PMA) and interleukin-1 (IL-1)-induced NF- $\kappa B$ activity(3). Shortly thereafter, Alain Isreal's group in Paris reported the identification of NEMO as well, by sequencing polypeptides that co-immunoprecipitated with IKK-1 antibody. These truncated mutants were two forms of differentially processed NEMO that bind to IKK-2 and can block NF- $\mathrm{KB}$ activation(20).

My laboratory's entry into the NF- $\kappa B$ field came by accident when Paulina Bull from Chile joined Tony Hunter's and my laboratory as a joint postdoctoral fellow. She did not want to work on Fos-Jun complex, a very active area of inquiry in my laboratory, because she felt it was a highly competitive field. She was the first to identify that c-rel was serum and TPA inducible. Like NF- $\mathrm{KB}$, it had a N-terminal regulatory domain and a C-terminal transactivation domain (21) (22). Later, our laboratory focused on investigating the regulators of NF- $\mathrm{KB}$ activation and identified an additional regulatory protein ELKS in the IKK complex. We were also one of the first groups to generate IKK1 and IKK2 knockout (KO) mice and reported their distinct functions in vivo. Lately, our laboratory's focus has been shifted to identifying NF- $\mathrm{KB}$-independent IKK functions. We identified p53 as a substrate for IKK2 phosphorylation and how this affects the stability of p53 (23). We also identified SNAP-23 as a target for IKK2 phosphorylation and its critical role in degranulation in mast cells (24). 


\section{Composition of IKK complex and its activation}

\section{Members of IKK complex}

Most biochemical assays studying purified IKK complex suggest that the IKK proteins exist in the complex at 1:1:2 ratio, supporting the notion that one IKK1 and IKK2 hetero-dimer is bound to dimers of NEMO (25-27). However, this does not exclude the existence of multiple forms of IKK complex, including IKK1 or IKK2 homodimers, associated with or distinct from NEMO. The fact that IKK2 can still function to activate NF-KB pathway in the absence of IKK1 in a NEMO dependent way is a direct proof that such dimers can exist and interact with NEMO. The two kinases of the IKK complex, IKK1 and IKK2, are highly homologous, sharing $51 \%$ of their sequence identities (17). They both have a kinase domain with two serine residues (S176 S180 for IKK1 and S177 S181 for IKK2) that require phosphorylation for the kinase functions (17-19, 28), a predicted leucine zipper (LZ) domain and a helix-loop-helix (HLH) domain (29), and a C-terminus NEMO-binding domain (NBD). In addition, IKK2 has a ubiquitin-like domain (ULD) that is not found on IKK1, with a key residue at L353 (30). Mutants where this domain is deleted can still form the IKK complex; however, the complex cannot activate NF- $\kappa B$ in response to stimuli such as IL-1 and TNF. Site-specific mutation of the L353 residue did not alter the ability of IKK2 to phosphorylate I $\mathrm{KB} \alpha$, but this IKK2 mutant was not able to dissociate from p65 subunits with or without stimuli. These studies suggest that ULD may be involved in the dissociation of IKK complex from the NF- $\kappa B$ proteins after the phosphorylation and degradation of I $\mathrm{B} \alpha$. However, recent studies of the crystal structure of IKK2 found that the predicted LZ and HLH motifs do not form those structures but instead are part of an elongated, $\alpha$-helical scaffold/dimerization domain (SDD)(31). Furthermore, the critical L353 residue was buried in the core of ULD and was not part of the protein interaction interface. It is possible that the L353A mutation caused structural change of ULD and thus disrupted normal functions of ULD. The structure also revealed that both the ULD and the SDD are involved in interaction with I $\mathrm{B} \beta \alpha$ and that SDD is essential for IKK2 dimerization. Structurally, IKK1 is very similar to IKK2, the only difference being IKK1 has a predicted nuclear localization signal (32). Although IKK1 has been shown to have nuclear activities independent of NF- $\kappa B$, the function of the IKK1 NLS is still not fully understood. It appears that the interaction of IKK1 with NEMO is weaker than that of IKK2, because a peptide mimic of the IKK and NEMO interaction site can disrupt IKK1 interaction with NEMO at a lower concentration than IKK2. Whether this weaker interaction with NEMO can explain the less stringent requirement of IKK1 in the IKK complex for activation of NF- $\mathrm{KB}$ is still a matter for debate.

NEMO lacks the catalytic domain found in IKK1 and IKK2 and is structurally very different from those two proteins. It is comprised of two coil-coil domains (CC), a LZ, and a zinc finger (ZF) domain (Reviewed in Ghosh et al., this volume). Structural data indicate that dimers of NEMO bind to both IKK1 and IKK2 homo- as well as hetero-dimers(33, 34). The $\mathrm{N}$-terminal portion of NEMO interacts with the NBD of the IKKs and such interaction is required for IKK activation. Furthermore, NEMO seems to have the ability to oligomerize via a minimal oligomerization domain (MOD) $(35,36)$. Mutations in this domain greatly reduce induced NF- $\mathrm{kB}$ activation, indicating that oligomerization of NEMO might be an important part of its function as a regulatory protein. Exactly how NEMO regulates IKK activity is still a mystery, but there is no doubt that it is a key regulator of IKK complex, both positively and negatively. Other than the ability of NEMO to oligomerize, its ability to bind to K63-linked polyubiquitin chains may also serve an important function in IKK activation. Several groups have shown that NEMO can recognize polyubiquitinated upstream kinases (37-39), such as receptor-interacting protein-1 (RIP1) or other adapter proteins. Studies with site-specific mutation that disrupts NEMO recognition of polyubiquitin shows that NF- $\mathrm{BB}$ response is greatly reduced. It is possible that NEMO may function as a chaperone protein that brings the IKK complex to upstream polyubiquitinated 
kinases, leading to IKK phosphorylation and activation. In addition to activation of IKK complex, NEMO may also function as a negative regulator of the IKK complex. IKK2 mutation in the NEMO binding domain has increased kinase activity in the absence of stimuli (40). Furthermore, phosphorylation of NEMO on S68, which is located in the region that interacts with IKKs can down regulate NF- $\mathrm{KB}$ activation in the presence of stimuli (40-42), providing the possibility that phosphorylation of NEMO can serve as a negative regulatory event. Additionally, NEMO has also been shown to interact with several negative regulatory proteins including the deubiquitinases A20 and CYLD (43-45), as well as protein phophatases PP2A and PP2C (46-48). These proteins have been postulated to remove phosphorylation in the activation T loop of IKKs, so in essence, NEMO may serve as a docking station for negative regulators as well. It is not clear how NEMO switches roles from being a regulator of IKK activation to a mediator of repression. It is, however, possible that NEMO carries out both functions at the same time, but the balance towards activation or deactivation is delicately controlled by the amount of co-factors induced by upstream signaling.

Another important function of NEMO that came into the spotlight recently is NEMO's role in nuclear-initiated NF- $\kappa \mathrm{B}$ signaling. The receptor-induced signals such as TNFR and TLR4 initiate IKK activation from the cytoplasm, where inactive NF- $\mathrm{kB}$ is sequestered. In contrast, DNA damage is a stress signal that initiates in the nucleus, yet the signals are relayed from the nucleus to the cytoplasm where activation of NF- $\mathrm{KB}$ occurs (Reviewed in McCool \& Miyamoto, this volume). Interestingly, NEMO's presence in the nucleus free of IKK1 and IKK2 seems to be essential for such signal relay. The current hypothesis is that activation of ATM by DNA damage and NEMO SUMOylation leads to nuclear export of both proteins as well as subsequent activation of TAK1, IKK, and NF- $\mathrm{KB}$ (49). This IKKindependent function of NEMO in the nucleus signifies the importance of the role of the members of IKK complex independently involved in the crosstalk between many signaling pathways.

There are other essential components of the IKK complex that regulate NF- $\mathrm{kB}$ signaling and perhaps more waiting to be discovered. These include heat shock protein 70 (HSP70), which interacts with NEMO to suppress NF- $\mathrm{kB}$ activation (50, 51), HSP90 and its co-chaperone Cdc37, which stabilize IKK complex(52), and ELKS, a regulatory component of the IKK complex identified by our group. ELKS was discovered by the same gel filtration and immunoprecipitation methods in stimulated 293T cells used to identify IKK1 and IKK2 (53). Silencing of ELKS by RNA interference (RNAi) blocked the induction of NF-KB target genes and protected the cells from apoptosis in response to TNF and IL- $1 \alpha$. Recent reports have also implicated a role for ELKS in the cellular response to ATM-dependent DNA double stranded break repair. After the attachment of K63-linked ubiquitin chains to ELKS in an ATM- and NEMO-dependent process, ELKS promotes the clustering of TAB2TAK1 and IKK complexes, thereby enhancing the proximity of the proteins and the subsequent activation of IKK and NF- $\mathrm{KB}(54,55)$. Ongoing biological characterizations of ELKS will hopefully shed more light on the detailed mechanism and interacting partners.

\section{IKK activation}

Activation of IKK complex requires phosphorylation of S176 and S180 on IKK1 and S177 and S181 on IKK2(17). This event likely leads to a conformational change in the activation loop, which renders the kinase domain catalytically active. Evidence also exists to support that dephosphorylation of IKK can restore their inactive state, because protein phosphatases such as PP2A can inactivate recombinant IKK, while phosphatase inhibitors can lead to the slow activation of IKK (2). 
Although it has been the subject of intense study since the initial discoveries of IKK1 and IKK2 in 1997, the complete mechanism by which the IKK complex becomes phosphorylated remains an important unanswered questions in NF- $\mathrm{KB}$ field. There appear to be two general lines of thoughts on this process. First, it is possible that IKKs can autophosphorylate each other. This idea was proposed because NF- $\mathrm{KB}$ activation by certain viral proteins, such as HTLV1 Tax (Reviewed in Chan \& Greene, this volume), does not seem to require any upstream kinase activity. Recent crystal structure studies revealed that it is less likely, at least in the case of a IKK2 homodimer, that IKK2 phosphorylates its dimer partner because of the large spacing (31). However, the IKK complex exists as holoenzyme of at least a dimer or dimers, and NEMO may play an important role in forming such complexes. NEMO has oligomerization domains, and can bind to polyubiquitinated substrates bringing bound IKK into close proximity with each other. More detailed structure data may shed light on this issue (Reviewed in Ghosh et al., this volume).

The second line of thought is that there are specific IKK kinases (IKKK) depending on the signals inducing the NF- $\mathrm{KB}$ activity. A few candidates have emerged, though none has been definitively proven. The most prominent one is TAK1 $(56,57)$, a MAPKK that is also involved in the c-Jun N-terminal kinase (JNK) pathway. It was discovered by co-eluting the enzyme with IKK-inducing activity in a cell-free assay (57). The mechanism proposed was that when IL-1 binds to the IL-1 receptor, which has the myeloid differentiation factor 88 (MyD88) and IL-1 receptor-associated kinase 1 (IRAK1) adapter proteins, the complex recruits TNF receptor-associated factor 6 (TRAF6) that can activate TAK1 after modification by polyubiquitination. TAK1, along with its cofactors TAB 1 and TAB2 in a complex, can then phosphorylate IKK2. Studies with deletion mutants demonstrate that IKK complex activation is dependent on the TAK1 kinase domain, and that this activity is ubiquitin dependent. However, contradicting evidence exists. Constitutively active TAK1, even in the presence of TRAF6, is unable to phosphorylate IKK2, and overexpression of TAK1 is insufficient to activate NF- $\mathrm{KB}$ (57). Furthermore, animal studies have demonstrated that TAK1 is dispensable for IKK activation in vivo, at least in certain cell types. While TAK1-deficient MEFs show significantly reduced levels of NF- $\kappa B$ activation, they are not entirely abolished. Additionally, while TAK1 was important for TLR, TNF, and IL-1induced NF- $\mathrm{BB}$ signaling, TAK1-deficient B-cells showed no deficits in NF- $\kappa \mathrm{B}$ activity (58). RNAi studies of the cofactors TAB1 and TAB2 also showed no deficit in NF- $\kappa B$ activation (59). Therefore, the requirement of TAK1 for IKK activation maybe cell type specific.

RIP1, a serine/threonine kinase, has also been postulated to play a role in IKK phosphorylation as it is required for TNF-mediated IKK activation $(60,61)$. It is also recruited by TRAFs and its overexpression leads to IKK activation. RIP1 KOs are deficient in IKK activation (61), yet the kinase activity itself appears to be dispensable, because when RIP1 KO cells are reconstituted with kinase dead mutant protein, NF- $\mathrm{KB}$ activation was restored (60).

MEKK3 (MAPK/ERK kinase kinase 3) was also shown to directly phosphorylate IKK in vitro using recombinant IKK2. Yang et al. (62) used MEKK3-deficient fibroblasts to demonstrate its importance in TNF-induced NF- $\mathrm{kB}$ activation downstream of RIP1. The cells showed no p65 DNA binding activity by gel shift and IкB $\alpha$ was not phosphorylated in an IKK kinase assay using deficient cells. Yet, the MEKK $3^{-/}$fibroblasts still had some

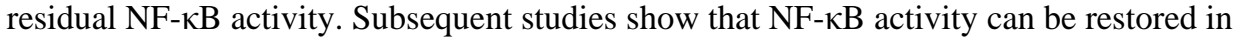
RIP1-deficient Jurkat T cells by fusing the RIP1 death domain to full length MEKK3 (63). The fusion protein is capable of interacting directly with TNF receptor-associated death domain (TRADD), indicating that RIP1 may act to recruit MEKK3 to the TNF- $\alpha$ receptor complex. These results may explain why the kinase activity of RIP1 is dispensable for IKK 
activation. Even so, the direct phosphorylation of the IKK by MEKK3 and its importance to $\mathrm{NF}-\kappa \mathrm{B}$ activation has not yet been demonstrated in vivo, due in part to the fact that $\mathrm{KO}$ mice die at embryonic day 10.5-11(64).

Our own efforts to find additional kinases that phosphorylate the IKK complex has been hampered by the limitations of siRNA screening. While the efficacy of siRNA knockdown has greatly improved over the last several years, the near impossibility of achieving $100 \%$ knockdown in an entire population of transfected or transduced cells means that some residual target kinase activity may remain, which is often enough to keep pathways unaltered. Future studies using small-molecule kinase inhibitors or KO MEFs may yield new information that finally allows for some clarity in answering this elusive question.

\section{Biological roles of the IKK proteins}

Since we have already mentioned many of the biochemical studies of IKK members in NF$\kappa \mathrm{B}$ signaling pathway in cell lines, here, the importance of each member for NF- $\kappa \mathrm{B}$ dependant functions is discussed further with the knowledge we gained through KO mouse models. Knockout of any of the three major components of the IKK complex leads to either embryonic developmental failure or neonatal developmental defects. Furthermore, KO of these components in specific cell types leads to many detrimental effects. The most important lesson learned from these KO mice is that IKK1 and IKK2 have distinct and nonredundant biological functions due to differing substrate specificities. We also discuss in detail the many NF- $\mathrm{kB}$-independent functions, focusing on some of the work our laboratory has done.

\section{NF-kB-dependant functions}

Our group generated IKK1 (65), IKK2 (66), and IKK1/IKK2 (67) KO mice by targeted gene disruption. Like the RelA KO mice (68) and NEMO KO mice, IKK2 KO mice die embryonically at approximately day E13, primarily due to massive liver apoptosis $(66,69)$. The lethal liver apoptosis is probably due to TNF signaling during embryogenesis, because IKK2 ${ }^{-/-}$MEF showed increased sensitivity to TNF-induced apoptosis. Furthermore the lethality of the $\mathrm{KO}$ could be rescued until a month after birth (longer if mice are kept in germ free facility) by crossing IKK2 KO mice to the TNFR ${ }^{-/}$mice. Hence IKK2 is essential in NF-KB signaling that rescues developing liver cell from TNF mediated apoptosis, and IKK1 does not have enough functional redundancy to prevent the liver damage (66). TNF-mediated apoptosis is not limited to the liver, since others have shown that tissue specific deletion of IKK2 can lead to similar consequences in the skin as well (70). It is worth noting though, mature hepatocyte-specific deletion of IKK2 surprisingly did not lead to liver damage, and NF- $\kappa B$ activation by TNF is functional in those cells (71). It is possible that hepatocytes during embryogenesis respond to TNF stimulation differently and have different requirement for NF- $\mathrm{KB}$ activation to such stimulus. Detailed mechanisms aside, these contradictory results strongly suggest a cell-type specific/developmental stage specific role of IKK2 in a biological system.

In contrast, IKK1-deficient mice can survive until a month after birth, yet they display striking developmental defects. Among these, newborn pups have shiny, taut, and sticky skin with a thicker, undifferentiated epidermis. They lack whiskers and their limbs fail to protrude from their trunk. MEFs derived from KO mice have diminished NF- $\kappa B$ activation after stimulation by IL-1 or TNF, but the IKK complex composed of IKK2 homodimers and NEMO is still capable of phosphorylating I $\mathrm{KB} \alpha$ and $\mathrm{I} \kappa \mathrm{B} \beta$ in vitro $(65,69,72)$, thus leading to the conclusion that IKK2 alone is sufficient for canonical NF- $\kappa B$ activation. However, sufficiency of IKK2 alone is not exclusive of the possibility that IKK1 plays a role in canonical NF- $\mathrm{BB}$ activation in the natural state of a cell. Our group as well as others have 
reported that NF- $\mathrm{KB}$-dependent gene expression in response to some canonical pathway stimuli occurs in IKK2-deficient MEFs $(66,73)$, but when NEMO is absent, this residual NF- $\kappa B$ activity is gone. Furthermore, Cao et al. (74) report that IKK1 is indispensible in receptor activator of NF- $\mathrm{KB}$ (RANK)-induced canonical NF- $\mathrm{KB}$ activation in mammary epithelial cells. Another interesting observation is that different stimuli may lead to different requirement for IKK complex formation in the same cell type. For instance, NEMO deficient MEFs were unable to respond to either TNF or IL-1, and little degradation of IkB $\alpha$ was observed, indicating the absolute requirement of NEMO for NF- $\mathrm{KB}$ activation. IKK1deficient MEFs were able to respond to both TNF and IL-1, however, IL-1, but not TNF, was able to induce IkB $\alpha$ degradation in IKK2-deficient cells and subsequent nuclear import of NF- $\kappa B$ proteins. This NF- $\kappa B$ activation by IL-1 in the absence of IKK2 is dependent on IKK1 interaction with NEMO because treatment with NEMO-binding domain peptide abolishes this activation (75). These data suggest that the absolute requirement for IKK2 in canonical NF- $\mathrm{\kappa B}$ activation is stimuli dependent, and IKK1 can substitute IKK2 functions at least in the case of IL-1 stimulation, though other cases may also exist.

We have also generated IKK1 IKK2 double KO mice, and they die at E12 due to enhanced apoptosis and defects in both neuralation and the fetal liver(67). MEFs derived from doubledeficient mice have no detectable NF- $\mathrm{KB}$ activity after stimulation with TNF, IL-1 $\alpha$, or lipopolysaccharide (LPS) by gel shift. Additionally, western blots examining I $\mathrm{B} \alpha$ and IкB $\beta$ kinetics showed no degradation after stimulation. In mice, TUNEL staining showed that double-deficient embryos fail to close the neural tube in the hindbrain due to apoptosis. Similar to IKK $2^{-/-}$mice, the double KO mice demonstrate severe hemorrhaging in the liver, but unlike the $\mathrm{IKK}^{-1-}$ mice, the double-KOs crossed with $\mathrm{TNFR}^{-1-}$ mice cannot be rescued and survive only marginally longer until day E16.5. The IKK $1^{-1-} \mathrm{IKK}^{-/-} \mathrm{TNFR}^{-1-}$ mice have morphology similar to IKK1 $1^{-1-}$ mice, yet they still have the neural tube defect. Finally, staining of NF- $\kappa B-L a c Z$ transgenic mice showed constitutive NF- $\kappa B$ activation during early vasculogenesis in wildtype mice, but almost no detectable activity in the double KO mice. Together, these data showed that IKK1 and IKK2 have some functional overlap in NF- $\mathrm{KB}$ dependant signaling pathway, but they are largely non-redundant with each playing an essential but different role in development.

NEMO deficiency seems to be a greater detriment to the classical NF- $\mathrm{kB}$ signaling pathway than either IKK1 or IKK2 deficiency alone. Cells lacking NEMO have no detectable NF- $\mathrm{KB}$ response to almost all pro-inflammatory, immune regulatory and pro-survival stimuli $(3,76$, 77). Furthermore, NEMO-deficient mice die during embryogenesis, similar to $\mathrm{IKK} 1^{-1-} \mathrm{IKK} 2^{-/-}$mice, through massive apoptosis in the developing liver due to their inability to turn on NF- $\mathrm{\kappa B}$ signaling in response to TNF stimulation. These results confirm the notion that NEMO is an indispensible regulator of IKK1 and IKK2 functions in the IKK complex during canonical NF- $\kappa \mathrm{B}$ signaling.

\section{NF-kB-independent pathway}

Other than their role in the NF- $\mathrm{KB}$ signaling pathway, both IKK2 and IKK1 have been shown to phosphorylate a growing list of substrates that are involved in a variety of biological functions including tumor suppression, immune functions, cell proliferation, and chromatin remodeling. Below we describe recent findings on the role of IKKs in NF- $\mathrm{KB}$ independent pathways, and a summary for both IKK1 and IKK2 are listed in Table 1. Most of these studies are based on effects of IKK1 or IKK2 KO on the biological activities of the substrate. Detailed mechanisms in many cases are still missing, such as how IKKs are recruited to phosphorylate specific targets under specific stimulus. However, recognizing the importance of NF- $\mathrm{KB}$-independent functions of IKKs is the first step towards understanding how these multi-functional kinases orchestrate crosstalk between different signaling pathways. 


\section{IKK2}

\section{Tumorigenesis}

IKK2 has been shown to phosphorylate several tumor suppressor proteins, the most prominent one being $\mathrm{p} 53$. Our laboratory was the first to raise the possibility that $\mathrm{p} 53$ is a substrate for IKK2 when sequence analysis of IKK2 substrates using synthetic IкB $\alpha$ peptides identified (D/A)S(G/L/D/R) \{G/D/R $\} X S$ as a consensus phosphorylation motif, and tumor suppressor gene 533 has this motif in its C-terminus (23). This finding raised the question whether IKK2 can regulate p53 stability and function by direct phosphorylation, given that 553 regulation is mainly through the phosphorylation at multiple sites in both $\mathrm{N}$ and C-terminus of the protein (78). Most of the p53 phosphorylation sites are induced by DNA damage and stress, and the phosphorylation stabilizes the protein by preventing Mdm2 mediated ubiquitination and degradation. However, certain sites (T155 by COP9 signalosome, T55 by TAF1, and S15 by Aurora A) were reported to target p53 for degradation (79-81). Indeed, phosphorylation of p53 by IKK2 at S362 and S366 is recognized by $\beta$-TrCP-mediated ubiquitination and proteasomal degradation (23). In agreement, IKK2-deficient MEF cells showed elevated p53 protein level in comparison to wildtype or IKK1-deficient cells(23). In addition, this observation was supported by in vivo data that p53 protein level was significantly increased when IKK2 is deleted by Villin-cre in intestinal epithelial cells (82). However, p53 phosphorylation at S362 and S366 or change of p53 protein level was not observed when cells were treated with TNF, which potently activated IKK complex to phosphorylate I $\mathrm{KB} \alpha$. In contrast, DNA-damaging reagents such as doxorubicin, which only moderately induced I $\mathrm{K} B \alpha$ phosphorylation, were sufficient to induce p53 phosphorylation at S362 and S366 through IKK2. These observations suggested that regulation of $\mathrm{p} 53$ stability by IKK2 is finely tuned by the microenvironment and nature of the stimulus. NF- $\mathrm{kB}$ dependent regulation of p53 through Mdm2 transcription has also been reported (83).

In turn, p53-deficient cells also exhibited elevated basal NF- $\kappa B$ activation (84). One of the possible mechanisms has been proposed to be high-level of glycolysis and abundance of active O-GlcNAcylation in p53-deficient cells. Constitutive O-GlcNAc IKK2 modification at inhibitory phosphorylation site (S771) has been found in these cells, which potentially increased its kinase activity (85). Dissection of the crosstalk between NF- $\mathrm{BB}$ and p53 pathways will be extremely important for understanding the inflammation-induced tumorigenesis, given that p53 silencing/mutation and NF- $\mathrm{kB}$ activation are the hallmarks of many human cancers. Recent studies from our laboratory has shown that loss of p53 impaired repression of NF- $\mathrm{kB}$ target gene transcription by glucocorticoids, providing evidence for a mechanism with which tumor cells can disrupt normal regulation of inflammatory process in the tumor microenvironment (86).

In addition to p53, there are other tumor suppressors that may be substrates for IKK2. TSC $1 / 2$ complex is an important tumor suppressor upstream of mTOR. In the static state, TSC1 binds to TSC2 and protects it from ubiquitination-mediated degradation.

Unexpectedly, IKK2 has been found to phosphorylate TSC1 upon pro-inflammatory stimuli such as TNF and IL-1 $\beta$, without Akt activation (87). Phosphorylation of TSC1 by IKK2 at S487 and S511 results in the suppression of TSC1/2 complex and induces mTOR activation. Given the critical role of mTOR pathway in tumorigenesis, this finding further emphasizes the link of inflammation and cancer (Reviewed in Baldwin, this volume). TSC1/2-deficient cells, unlike $\mathrm{p}^{-/-}$cells, have impaired NF- $\mathrm{kB}$ activation upon DNA damage or TNF stimulation. The underlying mechanism has not been fully clarified; however, it seems that high mTOR signal in TSC1/2 deficient cells may suppress Akt activity through a negative feedback regulation, which is important for the NF- $\mathrm{kB}$ activation upon certain stimuli(88). 
Another tumor suppressor that maybe regulated by IKK2 is FOXO3a. The Forkhead FOXO family of transcription factors is usually regulated by phosphorylation by Akt at conserved serine/threonine residues (89). However, IKK2 was found to regulate FOXO3a phosphorylation in the absence of Akt, and target FOXO3a to cytoplasm for ubiquitination mediated proteasomal degradation. This is supported by immunohistology of tumor specimens that FOXO3a is mainly expressed in cytoplasm where IKK2 expression is high (90).

Although IKK2 functions as a tumor promoting factor in most circumstances, in the case of regulating spindle formation, IKK2 can also act as a tumor suppressor. IKK2 knockdown cells were found to have defects in normal mitosis and the maintenance of spindle bipolarity. In these cells, Aurora A level is elevated due to the loss of phosphorylation by IKK2 and degradation by $\beta$ - TrCP pathway. High Aurora A activity in the cells leads to hyperactivation of mitotic motor KIF11 and deregulated bipolar spindle assembly; thus, the absence of IKK2 promotes genetic instability and oncogenic transformation (91).

\section{Regulating immune functions}

The role of NF- $\mathrm{KB}$ has been extensively studied in the immune system; however, IKK2 also has been shown to regulate immune response independent of NF- $\mathrm{KB}$ activation. Work from our laboratory has shown that IKK2 regulation of immunoglobulin E (IgE)-mediated mast cell degranulation plays a critical role in early-phase allergic reaction. Upon cross-linking of IgE receptor, IKK2 is recruited to lipid raft where it phosphorylates SNAP-23 at S95 and S120. Phosphorylation of SNAP-23 promotes its association with other SNARE proteins, and initiates membrane fusion and exocytosis in mast cells (24). Although the canonical NF$\kappa \mathrm{B}$ pathway is also indispensible for the TNF release in the late-phase allergic reactions, IKK2 regulation of SNARE complex assembly defines an essential NF- $\kappa B$-independent role in early-phase allergic response. It has been well studied in the early years that signals from antigen receptors (T-cell receptors and B-cell receptors) induce NF- $\mathrm{BB}$ activation and result in lymphocyte proliferation, cytokine production and isotype switching $(92,93$, reviewed in Gerondakis et al. and Kaileh \& Sen, this isvolumesue). The finding of NF-кB-independent role of IKK2 in anaphylactic reactions raises the question whether there are similar mechanisms to regulate immune response in other components of the immune system, such as macrophages, $\mathrm{T}$ and B lymphocytes.

\section{Crosstalk with the MAPK signaling pathway}

p105 is one of the NF- $\kappa B$ proteins that has C-terminal inhibitory region similar to IкB proteins. IKK 2 mediated p105 phosphorylation and proteolysis produce mature p50 protein. Interestingly, the p105 processing also releases a variety of other proteins, which are originally captured and inhibited by p105. Cot (TPL-2) is among these proteins (Reviewed in Gantke et al., this volume). In macrophages, IKK2 activity is increased by LPS stimulation. IKK2 induces p105 processing and releases p50 as well as cot, which in turn triggers the MEK and MAPK signal pathway $(94,95)$. IKK2 can also negatively regulate MAPK by direct phosphorylation of Dok1. Dok1 phosphorylation leads to Erk1/2 inhibition and impaired cell growth but increased cell mobility (96).

\section{Inflammation and diabetes}

The possible link between inflammation and diabetes has been a hot topic in recent studies and the role of IKK has been implicated. For example, IKK2 has been shown to phosphorylate IRS-1 at S312 upon TNF stimulation, which antagonizes insulin signaling downstream of IRS-1 (97). Surprisingly, conditional deletion of IKK2 in adult myocytes did not seem to prevent obesity-induced insulin resistance (98). It would be interesting to find out if adipose cell-specific deletion of IKK2 has an effect on the disease. 


\section{IKK1}

\section{Chromatin remodeling and transcription}

The study of IKK1 in regulating transcription complex started from the findings from two independent groups that IKK1 can shuttle from cytoplasm to nucleus and directly phosphorylate histone $\mathrm{H} 3$ at $\mathrm{S} 10$ upon TNF stimulation, which modulates the optimal expression of a group of NF- $\mathrm{kB}$ target gene $(99,100)$. This IKK1 regulation at chromatin level has been found in certain other genes as well, for example c-fos expression in epidermal growth factor-treated quiescent fibroblasts (101).

Kinase activity independent IKK1 regulation of chromatin has also been reported. In IKK1deficient keratinocytes, G2/M checkpoint molecule 14-3-3 $\delta$ protein level is low, due to Suv39h1-mediated histone H3 trimethylation. Reintroducing IKK1 (or its kinase-dead form IKK1 KA) back to the cells shields 14-3-3 $\delta$ gene locus from hypermethylation and restores its expression and normal G2/M checkpoint(102). This finding is fully consistent with two earlier reports showing that $14-3-3 \delta$ mutant mice (repeated epilation, $\mathrm{Er} /+$ ) have similar defects in skin development as IKK1 KO mice $(103,104)$.

Other than its ability to remodel chromatin, IKK1 can also directly regulate gene transcription by targeting co-activators. Phosphorylation of CBP by IKK1 at S1382 and S1386 has been identified to increase its intrinsic HAT (histone acetyltransferase) activity. More intriguingly, CBP phosphorylation by IKK1 also increases its affinity to NF- $\kappa B$ gene promoters versus $\mathrm{p} 53$ gene promoters, thus serving as a switch for turning on NF- $\mathrm{kB}$ genes and stimulating cell proliferation (105).

Steroid receptor coactivator SRC-3 is another protein regulated by IKK1 (and IKK2) phosphorylation. SRC-3 translocation from cytoplasm to nucleus is significantly enhanced by phosphorylation by IKK complex, which in turn increases the expression of proinflammatory NF- $\mathrm{kB}$ target genes (106).

\section{Cell cycle regulation}

$\beta$-catenin is an important transcription factor downstream of Wnt pathway, and it was one of the first alternative substrates of IKK1 identified outside of NF- $\mathrm{KB}$ pathway. $\beta$-catenin stability is regulated by GSK3 $\beta$ phosphorylation (threonine 41, serines 33 and 37) and proteasomal degradation (107). Interestingly, while IKK2 negatively regulates $\beta$-catenin stability similar to GSK3 $\beta$, IKK1 seems to increase $\beta$-catenin protein level and downstream signal, such as cyclin D1 transcription. These results suggested IKK1 may phosphorylate $\beta$ catenin at different residues and protect it from ubiquitination mediated degradation (108, 109). Moreover, a conflicting role of IKK1 in regulating cyclin D1 has been identified as well, based on the observation that IKK $1^{-/-} \mathrm{MEF}$ cells have high constitutive level of cyclin D1. IKK1 phosphorylation of cyclin D1 at threonine 298 is responsible for its fast degradation through a ubiquitination-dependent pathway (110). Thus, the role of the IKK complex in regulating $\beta$-catenin and cyclin D1 need to be considered in a context-dependent way, and more details are waiting for being investigated.

\section{Innate immune response}

Canonical NF- $\mathrm{\kappa B}$ activity regulates a set of important genes in the innate immune system, including cytokines and chemokines. However, IKK1 also regulates interferon response downstream of TLRs by directly phosphorylating interferon regulatory factors (IRFs). For example, phosphorylation of IRF7 by IKK1 serves as a positive regulator of interferon production (111). In contrast, phosphorylation of IRF5 by IKK1 has a negative role (112). 
The underlying mechanism for the two very similar factors undergoing completely opposite regulation still remains to be clarified.

\section{Tumor metastasis}

Although IKK1 acts at a tumor suppressor in squamous cell carcinomas, IKK1 has been shown to promote prostate cancer metastasis in TRAMP mice expressing SV40 T antigen in prostate epithelial cells. In late stage prostate cancer, infiltrating $\mathrm{T}$ cells and macrophages produce RANKL, which is thought to induce IKK1 nuclear accumulation, leading to the suppression of Maspin gene transcription resulting in increased metastasis. The reduced Maspin expression has been suggested to be a result of recruitment of an unknown DNA methyltransferase at the Maspin promoter region by phosphorylated nuclear IKK1(113).

\section{Kinase-independent function during development}

IKK1 KO mice showed defects in skin, limb, and skeleton development due to the crucial function of IKK1 in epidermis. This function has later been shown to be kinase activity- and NF- $\mathrm{KB}$-independent, because knockin of kinase dead IKK1 was able to rescue this phenotype (32). In keratinocytes, nuclear IKK1 induces cell cycle arrest and terminal differentiation, through regulating Smad2/3 target genes that function as Myc antagonists, including Mad1 (114). Indeed, the observation that IKK1 acts as a tumor suppressor in certain squamous cell carcinomas further supported this unique function (115).

\section{NEMO and human diseases}

Mutations in NEMO have been identified as the main genetic basis for three rare but devastating human diseases: incontinentia pigmnti (IP); X-linked recessive anhidrotic ectodermal dysplasia with immunodeficiency (EDA-ID); X-linked recessive anhidrotic ectodermal dysplasia with immunogdeficiency, osteopetrosis and lymphedema (OL-EDAID). IP is most commonly identified in female infants heterozygous for the mutated NEMO that is located on the $\mathrm{X}$-chromosome, while the male fetus usually dies in utero. IP patients have various developmental problems with varying degrees of severity, most commonly with the skin, eyes, teeth, and central nervous system (116). Female patients maturing into adulthood frequently exhibit skewed $\mathrm{X}$-inactivation, possibly due to the increased apoptosis of cells expressing the mutant NEMO. In contrast, EDA-ID and OL-EDA-ID usually are found in male infants that have inherited the recessive NEMO mutation from their heterozygous mothers. Physical manifestation of EDA-ID, also known as hypohidrotic ectodermal dysplasia with immune deficiency (HED-ID), commonly includes lack of sweat glands, sparse hair, and conical teeth. The degree of immunodeficiency can vary depending on the patient. A large number of patients have deficient antibody production, but other compartment of the immune systems can also show abnormality. Not surprisingly, HED-ID patients are susceptible to various bacterial, viral, and fungal infections, and few survive into adolescence. OL-EDA-ID patients develop lymphoedema in their hands and feet, as well as osteopetrosis in addition to all the symptoms of EAD-ID.

The International IP Consortium first reported in 2000 that most of the IP patients in their data bank have amorphic NEMO mutations and hence declared it as the cause of IP (117). The mutations are most commonly found in the coil-coil domain and the zinc finger domain, and frequently lead to improper expression of NEMO mRNA message. Cell lines were derived from IP abortus, and upon TNF or IL-1 stimulation, NF- $\mathrm{KB}$ translocation into the nucleus was undetectable. In addition, these cells have increased sensitivity to apoptotic signals. Immediately, following this discovery, Zonana et al. (118) reported that male infants from all four unrelated EDA-ID families they studied have mutations in the zinc finger domain of NEMO as well. The authors hypothesized that EDA-ID patients have the 
'less severe' forms of NEMO mutation than that of IP patients. Maybe partially functioning NEMO was able to allow male fetus harboring the mutation to post-natal survival, unlike the prenatal lethality seen in IP patients. However, experiments studying the extent of NF- $\mathrm{KB}$ inactivation by the mutated NEMO found in EDA-ID patients in comparison to that from IP patients were not tested. Some evidence supporting this hypothesis comes from studies of OL-EDA-ID patients. Doffinger et al. (116) reported that OL-EDA-ID patients harbor mutations in the stop codon of NEMO, which led to a 27 amino acid addition. Stimulation of PBMCs from these patients with IL-1 $\beta$, IL-18, TNF, LPS, as well as CD40L shows that these cells have impaired but not abolished NF- $\mathrm{BB}$ response, unlike that of complete abolishment in IP. Such partial impairment could lead to survival of the infant but also to high susceptibility to infection. Whether there is NEMO functional difference between the stop codon mutation and the Zinc finger domain and if such a difference exists can explain the phenotypic difference between EDA-ID and OL-EDA-ID is largely still a mystery.

\section{Targeting IKK}

Due to the prominent role of NF- $\mathrm{KB}$ signaling pathway in inflammatory disease and possible links to cancer and autoimmune diseases, drug development for inhibition of NF- $\mathrm{KB}$ has been hotly pursued by industry (Reviewed in Didonato et al., this volume). Inhibition of NF$\kappa \mathrm{B}$ can be achieved at various stages along the signaling pathway: (i) inhibition of the receptors at the cell surface membrane such as IL-1R and TNFR, (ii) inhibition of IKK complex, (iii) stabilizing the suppressor protein I $\kappa \mathrm{B}$ (Reviewed in Kanarek and Ben-Neriah, this volume), (iv) interference with the nuclear transport of NF- $\mathrm{\kappa B}$, and finally (v) inhibition of DNA binding of NF- $\kappa B$ proteins. The specificity of inhibition for NF- $\mathrm{BB}$ increases while the target range for such inhibition decreases in the order listed above. Targeting the IKK complex is attractive, because it has a perfect blend of pathway specificity and a broad range of downstream effects: there are no known NF- $\mathrm{BB}$ activities that do not require at least one of the IKK family members. Also due to the similarity of the kinase domains of IKK1 and IKK2 with other known protein kinases, many compounds have been screened to select for inhibition of IKK's kinase activity. So far, almost all of the compounds show greater inhibition of IKK2 than IKK1, and it is not clear why that is the case. The number of compounds that can inhibit IKK kinase activity is quite large. In Table 2, we have summarized the biological effects of a selected number of compounds that are being developed as IKK1 and IKK2 specific inhibitors (119-139). We have chosen these few due to their specificity for IKK inhibition and for the in vivo data available showing their efficacy.

Apart from inhibiting the kinase activity of IKK1 and IKK2, another approach is to target protein-protein interactions between the IKK complex members. The best success story in this approach is the NEMO-binding domain (NBD) peptide. The C-terminal hexapeptide core sequence present on both IKK1 and IKK2 is essential for their interaction with NEMO and for their activity. Therefore, not surprisingly, NBD peptides were able to competitively inhibit IKK1 and IKK2 interaction with NEMO (40). Interestingly, the concentration of NBD peptide required to inhibit IKK2 is much higher than that of IKK1, suggesting that IKK1 NBD interacts with NEMO at much lower affinity than IKK2. This observation fits well with the fact that IKK2 is of much greater importance in the canonical pathway than IKK1. In addition a modified NBD peptide that can easily traverse cell membranes has been shown to have great efficacy in entering cells and block signal induced NF- $\mathrm{KB}$ activation (140). A number of studies later also demonstrated that this modified NBD peptide has in vivo efficacy in animal models of inflammatory diseases, such as arthritis (141), colitis (142), and cerebral ischemia-reperfusion injury (143). Despite the success NBD peptide had in preclinical trials, its high cost and low stability may make it an unlikely candidate for pharmaceutical companies to pursue. 
Despite the intensive effort pouring into targeting IKK for therapeutics and the many positive results in preclinical studies, challenges lay ahead for the practical use of IKK inhibitors in disease treatment largely due to its pleiotropic effects. There are several layers of complexity to IKK's role in a cell. First, there are many signals that can induce NF-KB activation. These pathways converge at the IKK complex, yet, different downstream gene expression programs are induced that reflect the response to a particular stimuli. This specificity may come from the different upstream adaptor proteins, and it may come from differential IKK complex composition. Hence, design of drugs to inhibit NF- $\kappa B$ activation to a specific stimulus requires our full understanding of how IKK specificity is achieved. The second level of complexity comes from the many roles of IKK proteins, especially in NF-кB-independent pathways, including immune functions, cell survival, cell proliferation, and crosstalk between signaling pathways. Targeting IKK for therapeutics will likely lead to unwanted toxicity, and further understanding of IKK's many roles allow us to predict the risk and assess whether the risk outweigh the benefits. The third level of complexity comes from organism itself. In a disease model, different cells may require NF- $\kappa B$ activation for different purposes that maybe lead to different outcome for the disease progression. This case is best exemplified by the role of IKK2 in cancers. It has been reported in a mouse model of colitis that IKK2 deletion in the intestinal epithelia cells lead to increased apoptosis, while IKK2 deletion in myeloid cells lead to decreased pro-inflammatory cytokines production. The different functions of IKK2 in the two cell types led to different outcome of tumor progression (144). Therefore, when targeting IKK inhibition, it is important for us to understand the role of IKK activation in all tissue types of an organism.

\section{Perspectives}

conclusions and outstanding questions During the past two decades, the field has gained tremendous insight into the composition, activation, and regulation of the IKK complex. However, with every question answered, the complexity of NF- $\mathrm{KB}$ activation has revealed further signal-specific and cell-type specific regulation of NF- $\mathrm{\kappa B}$ by IKK complex. Another area that is underdeveloped but attracting attention is the downregulation of NF- $\mathrm{KB}$ signaling and the role of the IKK complex in this process. This could be an important mechanism of resolution of inflammation. Several deubiquitinases upstream of the IKK complex have been shown to be important for the downregulation of NF-kB activity, such as A20 and CYLD $(44,145)$. Deubiquitination of upstream binding partner of NEMO may interfere with the IKK holoenzyme formation (Reviewed in Harhaj \& Dixit, this issue). A20 expression is induced by NF- $\mathrm{KB}$ activation, while CYLD is not. Hence these two deubiquitinases also demonstrate that NF- $\mathrm{kB}$ can either be regulated by an auto-negative feedback loop or additional active suppression mechanisms. However, detailed mechanistic insight into the dissociation of IKK complex is still largely unknown. Given the important role of NF- $\mathrm{KB}$ signaling in inflammatory diseases and malignant diseases, knowledge in this process will be essential in developing new diagnostic and therapeutic tools.

\section{Acknowledgments}

IMV is an American Cancer Society Professor of Molecular Biology, and holds the Irwin and Joan Jacobs Chair in Exemplary Life Science. This work was supported in part by grants from the NIH (AI048034), Cancer Center Core Grant (P30 CA014195-38) Ipsen/Biomeasure, Sanofi Aventis, and the H.N. and Frances C. Berger Foundation.

\section{References}

1. Chen ZJ, Parent L, Maniatis T. Site-specific phosphorylation of IkappaBalpha by a novel ubiquitination-dependent protein kinase activity. Cell. 1996; 84:853-62. [PubMed: 8601309] 
2. DiDonato JA, Hayakawa M, Rothwarf DM, Zandi E, Karin M. A cytokine-responsive IkappaB kinase that activates the transcription factor NF-kappaB. Nature. 1997; 388:548-54. [PubMed: 9252186]

3. Yamaoka S, et al. Complementation cloning of NEMO, a component of the IkappaB kinase complex essential for NF-kappaB activation. Cell. 1998; 93:1231-40. [PubMed: 9657155]

4. Senftleben U, et al. Activation by IKKalpha of a second, evolutionary conserved, NF-kappa B signaling pathway. Science. 2001; 293:1495-9. [PubMed: 11520989]

5. Claudio E, Brown K, Park S, Wang H, Siebenlist U. BAFF-induced NEMO-independent processing of NF-kappa B2 in maturing B cells. Nat Immunol. 2002; 3:958-65. [PubMed: 12352969]

6. Dejardin E, et al. The lymphotoxin-beta receptor induces different patterns of gene expression via two NF-kappaB pathways. Immunity. 2002; 17:525-35. [PubMed: 12387745]

7. Hayden MS, Ghosh S. Signaling to NF-kappaB. Genes Dev. 2004; 18:2195-224. [PubMed: 15371334]

8. Beg AA, Baldwin AS Jr. The I kappa B proteins: multifunctional regulators of Rel/NF-kappa B transcription factors. Genes Dev. 1993; 7:2064-70. [PubMed: 8224838]

9. Gilmore TD, Morin PJ. The I kappa B proteins: members of a multifunctional family. Trends Genet. 1993; 9:427-33. [PubMed: 8122310]

10. Brockman JA, et al. Coupling of a signal response domain in I kappa B alpha to multiple pathways for NF-kappa B activation. Mol Cell Biol. 1995; 15:2809-18. [PubMed: 7739562]

11. Brown K, Gerstberger S, Carlson L, Franzoso G, Siebenlist U. Control of I kappa B-alpha proteolysis by site-specific, signal-induced phosphorylation. Science. 1995; 267:1485-8. [PubMed: 7878466]

12. Traenckner EB, Pahl HL, Henkel T, Schmidt KN, Wilk S, Baeuerle PA. Phosphorylation of human I kappa B-alpha on serines 32 and 36 controls I kappa B-alpha proteolysis and NF-kappa B activation in response to diverse stimuli. EMBO J. 1995; 14:2876-83. [PubMed: 7796813]

13. Whiteside ST, Ernst MK, LeBail O, Laurent-Winter C, Rice N, Israel A. N- and C-terminal sequences control degradation of MAD3/I kappa B alpha in response to inducers of NF-kappa B activity. Mol Cell Biol. 1995; 15:5339-45. [PubMed: 7565683]

14. DiDonato J, et al. Mapping of the inducible IkappaB phosphorylation sites that signal its ubiquitination and degradation. Mol Cell Biol. 1996; 16:1295-304. [PubMed: 8657102]

15. Chen Z, et al. Signal-induced site-specific phosphorylation targets I kappa B alpha to the ubiquitinproteasome pathway. Genes Dev. 1995; 9:1586-97. [PubMed: 7628694]

16. Scherer DC, Brockman JA, Chen Z, Maniatis T, Ballard DW. Signal-induced degradation of I kappa B alpha requires site-specific ubiquitination. Proc Natl Acad Sci U S A. 1995; 92:11259-63. [PubMed: 7479976]

17. Mercurio F, et al. IKK-1 and IKK-2: cytokine-activated IkappaB kinases essential for NF-kappaB activation. Science. 1997; 278:860-6. [PubMed: 9346484]

18. Regnier CH, Song HY, Gao X, Goeddel DV, Cao Z, Rothe M. Identification and characterization of an IkappaB kinase. Cell. 1997; 90:373-83. [PubMed: 9244310]

19. Woronicz JD, Gao X, Cao Z, Rothe M, Goeddel DV. IkappaB kinase-beta: NF-kappaB activation and complex formation with IkappaB kinase-alpha and NIK. Science. 1997; 278:866-9. [PubMed: 9346485]

20. Rothwarf DM, Zandi E, Natoli G, Karin M. IKK-gamma is an essential regulatory subunit of the IkappaB kinase complex. Nature. 1998; 395:297-300. [PubMed: 9751060]

21. Bull P, Morley KL, Hoekstra MF, Hunter T, Verma IM. The mouse c-rel protein has an N-terminal regulatory domain and a C-terminal transcriptional transactivation domain. Mol Cell Biol. 1990; 10:5473-85. [PubMed: 2204816]

22. Bull P, Hunter T, Verma IM. Transcriptional induction of the murine c-rel gene with serum and phorbol-12-myristate-13-acetate in fibroblasts. Mol Cell Biol. 1989; 9:5239-43. [PubMed: 2601720]

23. Xia Y, Padre RC, De Mendoza TH, Bottero V, Tergaonkar VB, Verma IM. Phosphorylation of p53 by IkappaB kinase 2 promotes its degradation by beta-TrCP. Proc Natl Acad Sci U S A. 2009; 106:2629-34. [PubMed: 19196987] 
24. Suzuki K, Verma IM. Phosphorylation of SNAP-23 by IkappaB kinase 2 regulates mast cell degranulation. Cell. 2008; 134:485-95. [PubMed: 18692471]

25. Hayden MS, Ghosh S. Shared principles in NF-kappaB signaling. Cell. 2008; 132:344-62. [PubMed: 18267068]

26. Scheidereit C. IkappaB kinase complexes: gateways to NF-kappaB activation and transcription. Oncogene. 2006; 25:6685-705. [PubMed: 17072322]

27. Hacker H, Karin M. Regulation and function of IKK and IKK-related kinases. Sci STKE. 2006; 2006:re13. [PubMed: 17047224]

28. Ling L, Cao Z, Goeddel DV. NF-kappaB-inducing kinase activates IKK-alpha by phosphorylation of Ser-176. Proc Natl Acad Sci U S A. 1998; 95:3792-7. [PubMed: 9520446]

29. Zandi E, Chen Y, Karin M. Direct phosphorylation of IkappaB by IKKalpha and IKKbeta: discrimination between free and NF-kappaB-bound substrate. Science. 1998; 281:1360-3. [PubMed: 9721103]

30. May MJ, Larsen SE, Shim JH, Madge LA, Ghosh S. A novel ubiquitin-like domain in IkappaB kinase beta is required for functional activity of the kinase. J Biol Chem. 2004; 279:45528-39. [PubMed: 15319427]

31. Xu G, et al. Crystal structure of inhibitor of kappaB kinase beta. Nature. 2011; 472:325-30. [PubMed: 21423167]

32. Sil AK, Maeda S, Sano Y, Roop DR, Karin M. IkappaB kinase-alpha acts in the epidermis to control skeletal and craniofacial morphogenesis. Nature. 2004; 428:660-4. [PubMed: 15071597]

33. Marienfeld RB, Palkowitsch L, Ghosh S. Dimerization of the I kappa B kinase-binding domain of NEMO is required for tumor necrosis factor alpha-induced NF-kappa B activity. Mol Cell Biol. 2006; 26:9209-19. [PubMed: 17000764]

34. Rushe M, et al. Structure of a NEMO/IKK-associating domain reveals architecture of the interaction site. Structure. 2008; 16:798-808. [PubMed: 18462684]

35. Agou F, et al. Inhibition of NF-kappa B activation by peptides targeting NF-kappa B essential modulator (nemo) oligomerization. J Biol Chem. 2004; 279:54248-57. [PubMed: 15466857]

36. Tegethoff S, Behlke J, Scheidereit C. Tetrameric oligomerization of IkappaB kinase gamma (IKKgamma) is obligatory for IKK complex activity and NF-kappaB activation. Mol Cell Biol. 2003; 23:2029-41. [PubMed: 12612076]

37. Tang ED, Wang CY, Xiong Y, Guan KL. A role for NF-kappaB essential modifier/IkappaB kinase-gamma (NEMO/IKKgamma) ubiquitination in the activation of the IkappaB kinase complex by tumor necrosis factor-alpha. J Biol Chem. 2003; 278:37297-305. [PubMed: 12867425]

38. Ea CK, Deng L, Xia ZP, Pineda G, Chen ZJ. Activation of IKK by TNFalpha requires site-specific ubiquitination of RIP1 and polyubiquitin binding by NEMO. Mol Cell. 2006; 22:245-57. [PubMed: 16603398]

39. Wu CJ, Conze DB, Li T, Srinivasula SM, Ashwell JD. Sensing of Lys 63-linked polyubiquitination by NEMO is a key event in NF-kappaB activation [corrected]. Nat Cell Biol. 2006; 8:398-406. [PubMed: 16547522]

40. May MJ, Marienfeld RB, Ghosh S. Characterization of the Ikappa B-kinase NEMO binding domain. J Biol Chem. 2002; 277:45992-6000. [PubMed: 12244103]

41. Schomer-Miller B, Higashimoto T, Lee YK, Zandi E. Regulation of IkappaB kinase (IKK) complex by IKKgamma-dependent phosphorylation of the T-loop and $\mathrm{C}$ terminus of IKKbeta. $\mathrm{J}$ Biol Chem. 2006; 281:15268-76. [PubMed: 16597623]

42. Delhase M, Hayakawa M, Chen Y, Karin M. Positive and negative regulation of IkappaB kinase activity through IKKbeta subunit phosphorylation. Science. 1999; 284:309-13. [PubMed: 10195894]

43. Brummelkamp TR, Nijman SM, Dirac AM, Bernards R. Loss of the cylindromatosis tumour suppressor inhibits apoptosis by activating NF-kappaB. Nature. 2003; 424:797-801. [PubMed: 12917690]

44. Kovalenko A, Chable-Bessia C, Cantarella G, Israel A, Wallach D, Courtois G. The tumour suppressor CYLD negatively regulates NF-kappaB signalling by deubiquitination. Nature. 2003; 424:801-5. [PubMed: 12917691] 
45. Zhang SQ, Kovalenko A, Cantarella G, Wallach D. Recruitment of the IKK signalosome to the p55 TNF receptor: RIP and A20 bind to NEMO (IKKgamma) upon receptor stimulation. Immunity. 2000; 12:301-11. [PubMed: 10755617]

46. Fu DX, Kuo YL, Liu BY, Jeang KT, Giam CZ. Human T-lymphotropic virus type I tax activates Ikappa B kinase by inhibiting I-kappa B kinase-associated serine/threonine protein phosphatase 2A. J Biol Chem. 2003; 278:1487-93. [PubMed: 12419799]

47. Hong $\mathrm{S}$, et al. Heptad repeats regulate protein phosphatase 2a recruitment to I-kappaB kinase gamma/NF-kappaB essential modulator and are targeted by human T-lymphotropic virus type 1 tax. J Biol Chem. 2007; 282:12119-26. [PubMed: 17314097]

48. Prajapati S, Verma U, Yamamoto Y, Kwak YT, Gaynor RB. Protein phosphatase 2Cbeta association with the IkappaB kinase complex is involved in regulating NF-kappaB activity. J Biol Chem. 2004; 279:1739-46. [PubMed: 14585847]

49. Miyamoto S. Nuclear initiated NF-kappaB signaling: NEMO and ATM take center stage. Cell Res. 2011; 21:116-30. [PubMed: 21187855]

50. Ran R, et al. Hsp70 promotes TNF-mediated apoptosis by binding IKK gamma and impairing NFkappa B survival signaling. Genes Dev. 2004; 18:1466-81. [PubMed: 15198984]

51. Weiss YG, et al. Enhanced heat shock protein 70 expression alters proteasomal degradation of IkappaB kinase in experimental acute respiratory distress syndrome. Crit Care Med. 2007; 35:2128-38. [PubMed: 17855826]

52. Chen G, Cao P, Goeddel DV. TNF-induced recruitment and activation of the IKK complex require Cdc37 and Hsp90. Mol Cell. 2002; 9:401-10. [PubMed: 11864612]

53. Ducut Sigala JL, Bottero V, Young DB, Shevchenko A, Mercurio F, Verma IM. Activation of transcription factor NF-kappaB requires ELKS, an IkappaB kinase regulatory subunit. Science. 2004; 304:1963-7. [PubMed: 15218148]

54. Wu ZH, Shi Y, Tibbetts RS, Miyamoto S. Molecular linkage between the kinase ATM and NFkappaB signaling in response to genotoxic stimuli. Science. 2006; 311:1141-6. [PubMed: 16497931]

55. Wu ZH, et al. ATM- and NEMO-dependent ELKS ubiquitination coordinates TAK1-mediated IKK activation in response to genotoxic stress. Mol Cell. 2010; 40:75-86. [PubMed: 20932476]

56. Ninomiya-Tsuji J, Kishimoto K, Hiyama A, Inoue J, Cao Z, Matsumoto K. The kinase TAK1 can activate the NIK-I kappaB as well as the MAP kinase cascade in the IL-1 signalling pathway. Nature. 1999; 398:252-6. [PubMed: 10094049]

57. Wang C, Deng L, Hong M, Akkaraju GR, Inoue J, Chen ZJ. TAK1 is a ubiquitin-dependent kinase of MKK and IKK. Nature. 2001; 412:346-51. [PubMed: 11460167]

58. Sato $\mathrm{S}$, et al. Essential function for the kinase TAK1 in innate and adaptive immune responses. Nat Immunol. 2005; 6:1087-95. [PubMed: 16186825]

59. Ishitani T, Takaesu G, Ninomiya-Tsuji J, Shibuya H, Gaynor RB, Matsumoto K. Role of the TAB2-related protein TAB3 in IL-1 and TNF signaling. EMBO J. 2003; 22:6277-88. [PubMed: 14633987]

60. Ting AT, Pimentel-Muinos FX, Seed B. RIP mediates tumor necrosis factor receptor 1 activation of NF-kappaB but not Fas/APO-1-initiated apoptosis. EMBO J. 1996; 15:6189-96. [PubMed: 8947041]

61. Meylan E, et al. RIP1 is an essential mediator of Toll-like receptor 3-induced NF-kappa B activation. Nat Immunol. 2004; 5:503-7. [PubMed: 15064760]

62. Yang J, et al. The essential role of MEKK3 in TNF-induced NF-kappaB activation. Nat Immunol. 2001; 2:620-4. [PubMed: 11429546]

63. Blonska M, You Y, Geleziunas R, Lin X. Restoration of NF-kappaB activation by tumor necrosis factor alpha receptor complex-targeted MEKK3 in receptor-interacting protein-deficient cells. Mol Cell Biol. 2004; 24:10757-65. [PubMed: 15572679]

64. Yang J, et al. Mekk3 is essential for early embryonic cardiovascular development. Nat Genet. 2000; 24:309-13. [PubMed: 10700190]

65. Li Q, et al. IKK1-deficient mice exhibit abnormal development of skin and skeleton. Genes Dev. 1999; 13:1322-8. [PubMed: 10346820] 
66. Li Q, Van Antwerp D, Mercurio F, Lee KF, Verma IM. Severe liver degeneration in mice lacking the IkappaB kinase 2 gene. Science. 1999; 284:321-5. [PubMed: 10195897]

67. Li Q, Estepa G, Memet S, Israel A, Verma IM. Complete lack of NF-kappaB activity in IKK1 and IKK2 double-deficient mice: additional defect in neurulation. Genes Dev. 2000; 14:1729-33. [PubMed: 10898787]

68. Beg AA, Sha WC, Bronson RT, Ghosh S, Baltimore D. Embryonic lethality and liver degeneration in mice lacking the RelA component of NF-kappa B. Nature. 1995; 376:167-70. [PubMed: 7603567]

69. Li ZW, et al. The IKKbeta subunit of IkappaB kinase (IKK) is essential for nuclear factor kappaB activation and prevention of apoptosis. J Exp Med. 1999; 189:1839-45. [PubMed: 10359587]

70. Pasparakis M, et al. TNF-mediated inflammatory skin disease in mice with epidermis-specific deletion of IKK2. Nature. 2002; 417:861-6. [PubMed: 12075355]

71. Luedde T, et al. Deletion of IKK2 in hepatocytes does not sensitize these cells to TNF-induced apoptosis but protects from ischemia/reperfusion injury. J Clin Invest. 2005; 115:849-59. [PubMed: 15776110]

72. Hu Y, Baud V, Oga T, Kim KI, Yoshida K, Karin M. IKKalpha controls formation of the epidermis independently of NF-kappaB. Nature. 2001; 410:710-4. [PubMed: 11287960]

73. Li X, et al. IKKalpha, IKKbeta, and NEMO/IKKgamma are each required for the NF-kappa Bmediated inflammatory response program. J Biol Chem. 2002; 277:45129-40. [PubMed: 12221085]

74. Cao Y, et al. IKKalpha provides an essential link between RANK signaling and cyclin D1 expression during mammary gland development. Cell. 2001; 107:763-75. [PubMed: 11747812]

75. Solt LA, Madge LA, Orange JS, May MJ. Interleukin-1-induced NF-kappaB activation is NEMOdependent but does not require IKKbeta. J Biol Chem. 2007; 282:8724-33. [PubMed: 17244613]

76. Makris C, et al. Female mice heterozygous for IKK gamma/NEMO deficiencies develop a dermatopathy similar to the human X-linked disorder incontinentia pigmenti. Mol Cell. 2000; 5:969-79. [PubMed: 10911991]

77. Rudolph D, et al. Severe liver degeneration and lack of NF-kappaB activation in NEMO/ IKKgamma-deficient mice. Genes Dev. 2000; 14:854-62. [PubMed: 10766741]

78. Toledo F, Wahl GM. Regulating the p53 pathway: in vitro hypotheses, in vivo veritas. Nat Rev Cancer. 2006; 6:909-23. [PubMed: 17128209]

79. Bech-Otschir D, et al. COP9 signalosome-specific phosphorylation targets p53 to degradation by the ubiquitin system. EMBO J. 2001; 20:1630-9. [PubMed: 11285227]

80. Katayama H, et al. Phosphorylation by aurora kinase A induces Mdm2-mediated destabilization and inhibition of p53. Nat Genet. 2004; 36:55-62. [PubMed: 14702041]

81. Li HH, Li AG, Sheppard HM, Liu X. Phosphorylation on Thr-55 by TAF1 mediates degradation of p53: a role for TAF1 in cell G1 progression. Mol Cell. 2004; 13:867-78. [PubMed: 15053879]

82. Egan LJ, et al. IkappaB-kinasebeta-dependent NF-kappaB activation provides radioprotection to the intestinal epithelium. Proc Natl Acad Sci U S A. 2004; 101:2452-7. [PubMed: 14983030]

83. Tergaonkar V, Pando M, Vafa O, Wahl G, Verma I. p53 stabilization is decreased upon NFkappaB activation: a role for NFkappaB in acquisition of resistance to chemotherapy. Cancer Cell. 2002; 1:493-503. [PubMed: 12124178]

84. Kawauchi K, Araki K, Tobiume K, Tanaka N. p53 regulates glucose metabolism through an IKKNF-kappaB pathway and inhibits cell transformation. Nat Cell Biol. 2008; 10:611-8. [PubMed: 18391940]

85. Kawauchi K, Araki K, Tobiume K, Tanaka N. Loss of p53 enhances catalytic activity of IKKbeta through O-linked beta-N-acetyl glucosamine modification. Proc Natl Acad Sci U S A. 2009; 106:3431-6. [PubMed: 19202066]

86. Murphy SH, et al. Tumor suppressor protein (p)53, is a regulator of NF-kappaB repression by the glucocorticoid receptor. Proc Natl Acad Sci U S A. 2011; 108:17117-22. [PubMed: 21949408]

87. Lee DF, et al. IKK beta suppression of TSC1 links inflammation and tumor angiogenesis via the mTOR pathway. Cell. 2007; 130:440-55. [PubMed: 17693255] 
88. Ghosh S, et al. Essential role of tuberous sclerosis genes TSC1 and TSC2 in NF-kappaB activation and cell survival. Cancer Cell. 2006; 10:215-26. [PubMed: 16959613]

89. Brunet A, et al. Akt promotes cell survival by phosphorylating and inhibiting a Forkhead transcription factor. Cell. 1999; 96:857-68. [PubMed: 10102273]

90. Hu MC, et al. IkappaB kinase promotes tumorigenesis through inhibition of forkhead FOXO3a. Cell. 2004; 117:225-37. [PubMed: 15084260]

91. Irelan JT, et al. A role for IkappaB kinase 2 in bipolar spindle assembly. Proc Natl Acad Sci U S A. 2007; 104:16940-5. [PubMed: 17939994]

92. Thome M, Tschopp J. TCR-induced NF-kappaB activation: a crucial role for Carma1, Bcl10 and MALT1. Trends Immunol. 2003; 24:419-24. [PubMed: 12909454]

93. Thome M. CARMA1, BCL-10 and MALT1 in lymphocyte development and activation. Nat Rev Immunol. 2004; 4:348-59. [PubMed: 15122200]

94. Waterfield M, Jin W, Reiley W, Zhang M, Sun SC. IkappaB kinase is an essential component of the Tpl2 signaling pathway. Mol Cell Biol. 2004; 24:6040-8. [PubMed: 15199157]

95. Beinke S, Robinson MJ, Hugunin M, Ley SC. Lipopolysaccharide activation of the TPL-2/MEK/ extracellular signal-regulated kinase mitogen-activated protein kinase cascade is regulated by IkappaB kinase-induced proteolysis of NF-kappaB1 p105. Mol Cell Biol. 2004; 24:9658-67. [PubMed: 15485931]

96. Lee S, et al. IkappaB kinase beta phosphorylates Dok1 serines in response to TNF, IL-1, or gamma radiation. Proc Natl Acad Sci U S A. 2004; 101:17416-21. [PubMed: 15574499]

97. Gao Z, et al. Serine phosphorylation of insulin receptor substrate 1 by inhibitor kappa B kinase complex. J Biol Chem. 2002; 277:48115-21. [PubMed: 12351658]

98. Rohl M, et al. Conditional disruption of IkappaB kinase 2 fails to prevent obesity-induced insulin resistance. J Clin Invest. 2004; 113:474-81. [PubMed: 14755344]

99. Yamamoto Y, Verma UN, Prajapati S, Kwak YT, Gaynor RB. Histone H3 phosphorylation by IKK-alpha is critical for cytokine-induced gene expression. Nature. 2003; 423:655-9. [PubMed: 12789342]

100. Anest V, Cogswell PC, Baldwin AS Jr. IkappaB kinase alpha and p65/RelA contribute to optimal epidermal growth factor-induced c-fos gene expression independent of IkappaBalpha degradation. J Biol Chem. 2004; 279:31183-9. [PubMed: 15155743]

101. Anest V, Hanson JL, Cogswell PC, Steinbrecher KA, Strahl BD, Baldwin AS. A nucleosomal function for IkappaB kinase-alpha in NF-kappaB-dependent gene expression. Nature. 2003; 423:659-63. [PubMed: 12789343]

102. Zhu F, Xia X, Liu B, Shen J, Hu Y, Person M. IKKalpha shields 14-3-3sigma, a G(2)/M cell cycle checkpoint gene, from hypermethylation, preventing its silencing. Mol Cell. 2007; 27:214 27. [PubMed: 17643371]

103. Herron BJ, et al. A mutation in stratifin is responsible for the repeated epilation (Er) phenotype in mice. Nat Genet. 2005; 37:1210-2. [PubMed: 16200063]

104. Li Q, Lu Q, Estepa G, Verma IM. Identification of 14-3-3sigma mutation causing cutaneous abnormality in repeated-epilation mutant mouse. Proc Natl Acad Sci U S A. 2005; 102:1597782. [PubMed: 16239341]

105. Huang WC, Ju TK, Hung MC, Chen CC. Phosphorylation of CBP by IKKalpha promotes cell growth by switching the binding preference of CBP from p53 to NF-kappaB. Mol Cell. 2007; 26:75-87. [PubMed: 17434128]

106. Wu RC, et al. Regulation of SRC-3 (pCIP/ACTR/AIB-1/RAC-3/TRAM-1) Coactivator activity by I kappa B kinase. Mol Cell Biol. 2002; 22:3549-61. [PubMed: 11971985]

107. Liu C, et al. Control of beta-catenin phosphorylation/degradation by a dual-kinase mechanism. Cell. 2002; 108:837-47. [PubMed: 11955436]

108. Lamberti C, et al. Regulation of beta-catenin function by the IkappaB kinases. J Biol Chem. 2001; 276:42276-86. [PubMed: 11527961]

109. Carayol N, Wang CY. IKKalpha stabilizes cytosolic beta-catenin by inhibiting both canonical and non-canonical degradation pathways. Cell Signal. 2006; 18:1941-6. [PubMed: 16616828] 
110. Kwak YT, Li R, Becerra CR, Tripathy D, Frenkel EP, Verma UN. IkappaB kinase alpha regulates subcellular distribution and turnover of cyclin D1 by phosphorylation. J Biol Chem. 2005; 280:33945-52. [PubMed: 16103118]

111. Hoshino K, et al. IkappaB kinase-alpha is critical for interferon-alpha production induced by Tolllike receptors 7 and 9. Nature. 2006; 440:949-53. [PubMed: 16612387]

112. Balkhi MY, Fitzgerald KA, Pitha PM. IKKalpha negatively regulates IRF-5 function in a MyD88-TRAF6 pathway. Cell Signal. 2010; 22:117-27. [PubMed: 19786094]

113. Luo JL, et al. Nuclear cytokine-activated IKKalpha controls prostate cancer metastasis by repressing Maspin. Nature. 2007; 446:690-4. [PubMed: 17377533]

114. Descargues $P$, et al. IKKalpha is a critical coregulator of a Smad4-independent TGFbeta-Smad2/3 signaling pathway that controls keratinocyte differentiation. Proc Natl Acad Sci U S A. 2008; 105:2487-92. [PubMed: 18268325]

115. Liu B, et al. IKKalpha is required to maintain skin homeostasis and prevent skin cancer. Cancer Cell. 2008; 14:212-25. [PubMed: 18772111]

116. Doffinger R, et al. X-linked anhidrotic ectodermal dysplasia with immunodeficiency is caused by impaired NF-kappaB signaling. Nat Genet. 2001; 27:277-85. [PubMed: 11242109]

117. Smahi A, et al. Genomic rearrangement in NEMO impairs NF-kappaB activation and is a cause of incontinentia pigmenti. The International Incontinentia Pigmenti (IP) Consortium. Nature. 2000; 405:466-72. [PubMed: 10839543]

118. Zonana J, et al. A novel X-linked disorder of immune deficiency and hypohidrotic ectodermal dysplasia is allelic to incontinentia pigmenti and due to mutations in IKK-gamma (NEMO). Am J Hum Genet. 2000; 67:1555-62. [PubMed: 11047757]

119. Onai $Y$, et al. Inhibition of IkappaB phosphorylation in cardiomyocytes attenuates myocardial ischemia/reperfusion injury. Cardiovasc Res. 2004; 63:51-9. [PubMed: 15194461]

120. Onai Y, et al. Inhibition of NF-\{kappa\}B improves left ventricular remodeling and cardiac dysfunction after myocardial infarction. Am J Physiol Heart Circ Physiol. 2007; 292:H530-8. [PubMed: 16920808]

121. Inayama M, et al. A novel IkappaB kinase-beta inhibitor ameliorates bleomycin-induced pulmonary fibrosis in mice. Am J Respir Crit Care Med. 2006; 173:1016-22. [PubMed: 16456147]

122. Sugita A, et al. Antiallergic and anti-inflammatory effects of a novel I kappaB kinase beta inhibitor, IMD-0354, in a mouse model of allergic inflammation. Int Arch Allergy Immunol. 2009; 148:186-98. [PubMed: 18849610]

123. Tanaka A, Muto S, Jung K, Itai A, Matsuda H. Topical application with a new NF-kappaB inhibitor improves atopic dermatitis in NC/NgaTnd mice. J Invest Dermatol. 2007; 127:855-63. [PubMed: 17068475]

124. Yang J, Amiri KI, Burke JR, Schmid JA, Richmond A. BMS-345541 targets inhibitor of kappaB kinase and induces apoptosis in melanoma: involvement of nuclear factor kappaB and mitochondria pathways. Clin Cancer Res. 2006; 12:950-60. [PubMed: 16467110]

125. Burke JR, et al. BMS-345541 is a highly selective inhibitor of I kappa B kinase that binds at an allosteric site of the enzyme and blocks NF-kappa B-dependent transcription in mice. J Biol Chem. 2003; 278:1450-6. [PubMed: 12403772]

126. Everhart MB, et al. Duration and intensity of NF-kappaB activity determine the severity of endotoxin-induced acute lung injury. J Immunol. 2006; 176:4995-5005. [PubMed: 16585596]

127. Newton R, et al. Repression of inflammatory gene expression in human pulmonary epithelial cells by small-molecule IkappaB kinase inhibitors. J Pharmacol Exp Ther. 2007; 321:734-42. [PubMed: 17322026]

128. Chapoval SP, et al. Inhibition of NF-kappaB activation reduces the tissue effects of transgenic IL-13. J Immunol. 2007; 179:7030-41. [PubMed: 17982094]

129. Yemelyanov A, et al. Effects of IKK inhibitor PS1145 on NF-kappaB function, proliferation, apoptosis and invasion activity in prostate carcinoma cells. Oncogene. 2006; 25:387-98. [PubMed: 16170348]

130. Khanbolooki S, et al. Nuclear factor-kappaB maintains TRAIL resistance in human pancreatic cancer cells. Mol Cancer Ther. 2006; 5:2251-60. [PubMed: 16985059] 
131. Ziegelbauer K, et al. A selective novel low-molecular-weight inhibitor of IkappaB kinase-beta (IKK-beta) prevents pulmonary inflammation and shows broad anti-inflammatory activity. Br J Pharmacol. 2005; 145:178-92. [PubMed: 15753951]

132. Moss NC, Stansfield WE, Willis MS, Tang RH, Selzman CH. IKKbeta inhibition attenuates myocardial injury and dysfunction following acute ischemia-reperfusion injury. Am J Physiol Heart Circ Physiol. 2007; 293:H2248-53. [PubMed: 17675566]

133. Frelin C, Imbert V, Griessinger E, Loubat A, Dreano M, Peyron JF. AS602868, a pharmacological inhibitor of IKK2, reveals the apoptotic potential of TNF-alpha in Jurkat leukemic cells. Oncogene. 2003; 22:8187-94. [PubMed: 14603259]

134. Beraza N, et al. Pharmacological IKK2 inhibition blocks liver steatosis and initiation of nonalcoholic steatohepatitis. Gut. 2008; 57:655-63. [PubMed: 18408102]

135. Lentsch AB. Activation and function of hepatocyte NF-kappaB in postischemic liver injury. Hepatology. 2005; 42:216-8. [PubMed: 15962293]

136. Birrell MA, et al. Ikappa-B kinase-2 inhibitor blocks inflammation in human airway smooth muscle and a rat model of asthma. Am J Respir Crit Care Med. 2005; 172:962-71. [PubMed: 16002568]

137. Izmailova ES, et al. Use of molecular imaging to quantify response to IKK-2 inhibitor treatment in murine arthritis. Arthritis Rheum. 2007; 56:117-28. [PubMed: 17195214]

138. Schopf L, et al. IKKbeta inhibition protects against bone and cartilage destruction in a rat model of rheumatoid arthritis. Arthritis Rheum. 2006; 54:3163-73. [PubMed: 17009244]

139. Podolin PL, et al. Attenuation of murine collagen-induced arthritis by a novel, potent, selective small molecule inhibitor of IkappaB Kinase 2, TPCA-1 (2-[(aminocarbonyl)amino]-5-(4fluorophenyl)-3-thiophenecarboxamide), occurs via reduction of proinflammatory cytokines and antigen-induced T cell Proliferation. J Pharmacol Exp Ther. 2005; 312:373-81. [PubMed: 15316093]

140. May MJ, D'Acquisto F, Madge LA, Glockner J, Pober JS, Ghosh S. Selective inhibition of NFkappaB activation by a peptide that blocks the interaction of NEMO with the IkappaB kinase complex. Science. 2000; 289:1550-4. [PubMed: 10968790]

141. Dai S, Hirayama T, Abbas S, Abu-Amer Y. The IkappaB kinase (IKK) inhibitor, NEMO-binding domain peptide, blocks osteoclastogenesis and bone erosion in inflammatory arthritis. J Biol Chem. 2004; 279:37219-22. [PubMed: 15252035]

142. Shibata W, et al. Cutting edge: The IkappaB kinase (IKK) inhibitor, NEMO-binding domain peptide, blocks inflammatory injury in murine colitis. J Immunol. 2007; 179:2681-5. [PubMed: 17709478]

143. Desai A, Singh N, Raghubir R. Neuroprotective potential of the NF-kappaB inhibitor peptide IKK-NBD in cerebral ischemia-reperfusion injury. Neurochem Int. 2010; 7:876-83. [PubMed: 20868715]

144. Greten FR, et al. IKKbeta links inflammation and tumorigenesis in a mouse model of colitisassociated cancer. Cell. 2004; 118:285-96. [PubMed: 15294155]

145. Lee EG, et al. Failure to regulate TNF-induced NF-kappaB and cell death responses in A20deficient mice. Science. 2000; 289:2350-4. [PubMed: 11009421] 
Table 1

\begin{tabular}{|c|c|c|c|}
\hline Biological functions & Kinase / substrate & Detailed description & Reference \\
\hline \multirow{6}{*}{ Tumorigenesis } & IKK2 / P53 & Destabilizing P53 & 23 \\
\hline & $\mathrm{IKK} 2 / \mathrm{TSC} 1 / 2$ & Suppress TSC1/2, induce mTOR activation & 87,88 \\
\hline & IKK2 / FOXO3a & Target FOXO3a for proteasomal degradation & 89,90 \\
\hline & IKK2 / AuroraA & Target AuroraA degradation by $\beta$-TrCP pathway & 91 \\
\hline & IKK1 / unknown & Suppress Mapsin, increase metastatogenesis & 113 \\
\hline & IKK1 / unknown & Regulate Smad2/3 Target genes that function as Myc antagonists & 114 \\
\hline \multirow{3}{*}{ Immune functions } & IKK2 / SNAP23 & Promote exocytosis in mast cells & 24 \\
\hline & IKK1 / IRF7 & Increase IFN production upon TLR stimulation & 111 \\
\hline & IKK1 / IRF5 & Decrease IFN production upon TLR stimulation & 112 \\
\hline \multirow{4}{*}{ Transcriptional regulation } & IKK1 / Histone H3 & $\begin{array}{l}\text { Regulate optimal expression of NF-אB genes upon TNF } \\
\text { stimulation }\end{array}$ & 99,100 \\
\hline & IKK1 / no substrate & Stabilize G2/M checkpoint $14-3-3 \sigma$ protein gene expression & 102 \\
\hline & IKK1 / CBP & $\begin{array}{l}\text { Increase CBP histone acetyltransferase activity, increase its } \\
\text { affinity for NF- } \kappa \text { B promoter }\end{array}$ & 105 \\
\hline & IKK1 and IKK2 / SRC-3 & Increase pro-inflammatory gene expression & 106 \\
\hline \multirow{2}{*}{ Cell cycle } & IKK1 / $\beta$-catenin & Protect $\beta$-catenin from ubiquitination mediated degradation & $107,108,109$ \\
\hline & IKK1 / cyclin D1 & Fast degradation of cyclin D1 through ubiquitination pathway & 110 \\
\hline \multirow{2}{*}{ Crosstalk between pathways } & IKK2 / p105 & Activate MEK and MAPK pathways via p105 proteolysis & 94,95 \\
\hline & IKK2 / Dok1 & Suppress MAPK Dok1 phosphorylation that inhibits Erk1/2 & 96 \\
\hline Diabetes & IKK2 / IRS-1 & Antagonize insulin signaling downstream of IRS-1 & 97 \\
\hline
\end{tabular}




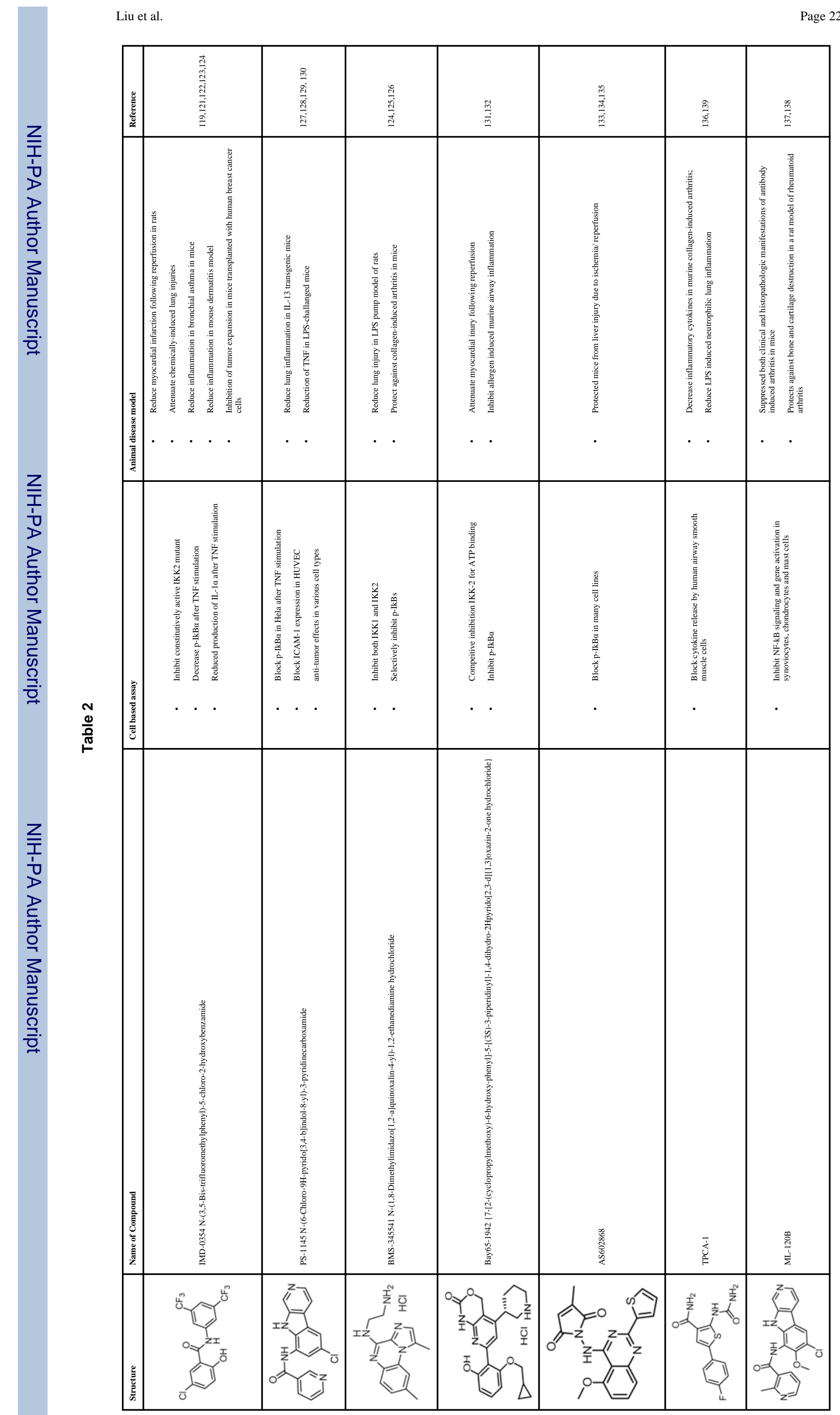

Immunol Rev. Author manuscript; available in PMC 2013 March 1. 